\title{
Metastatic Oesophagus Carcinoma Presented with Neck and Arm Pain: A Case Report
}

\author{
Özlem Demircioğlu1 ${ }^{1}$, Berat Meryem Alkan'1, Fatma Fidan'1, Aliye Tosun'1, Selami Akkuş² \\ ${ }^{1}$ PMR Clinic, Atatürk Educational and Research Hospital, Ankara, Turkey \\ ${ }^{2}$ PMR Clinic, Yıldırım Beyazıt University, Ankara, Turkey \\ Email: berat.alkan@ttmail.com
}

Received 6 February 2014; revised 5 March 2014; accepted 2 April 2014

Copyright @ 2014 by authors and Scientific Research Publishing Inc.

This work is licensed under the Creative Commons Attribution International License (CC BY). http://creativecommons.org/licenses/by/4.0/

c) (i) Open Access

\begin{abstract}
Oesophageal carcinoma is among malignancies with poor prognosis due to the late onset symptoms related with large submucosal involvement, early lymphatic metastasis and its multicentric characteristics, majority of the patients decrease within the first year of diagnosis. However, bone metastasis is uncommon and reported to be $1 \%$ to $14 \%$ in autopsy series. Herein we report a case that was admitted to our outpatient clinics with severe neck and arm pain as presenting symptoms and diagnosed as metastatic oesophageal carcinoma afterwards.
\end{abstract}

\section{Keywords}

Oesophageal Carcinoma, Metastasis, Bone Metastasis

\section{Introduction}

Oesophageal cancer is one of the deadliest cancers in the world. The life time risk is about $0.8 \%$ for men and $0.3 \%$ for women. Incidence of oesophageal cancer is 13 cases per 100,000 population for black American men. On the whole, it is the sixth most common cause of cancer-related deaths in the world [1].

Since oesophageal carcinoma is among malignancies with poor prognosis due to the late onset symptoms related with large submucosal involvement, early lymphatic metastasis and its multicentric chacteristics, majority of the patients decrease within the first year of diagnosis. Mean 5-year survival rate is $8 \%-20 \%$ [2]. However, bone metastasis is uncommon and reported to be $1 \%$ to $14 \%$ in autopsy series [3].

Herein we report a case that was admitted to our outpatient clinics with severe neck and arm pain as presenting symptoms and diagnosed as metastatic oesophageal carcinoma afterwards. 


\section{Case Report}

42-year-old male patient was admitted to our outpatient clinics with severe neck and left arm pain. He indicated that pain was present for 2 months and had received medical treatment and thermal hydrotherapy with the diagnosis of cervical spondylosis in another center. He also described nocturnal pain and difficulty in swallowing. Smoking (more than 20 cigarettes per day) and alcohol consumption were present for nearly 20 years. On physical examination, cervical range-of-motion was quite painful and limited in all directions, left shoulder flexion and abduction strength was 3/5, and left elbow flexion and extension strength was 4/5. On laboratory examination, hemoglobin was $11.7 \mathrm{~g} / \mathrm{dl}$ (13.5 - 18), hematocrite \% 36, ESR $25 \mathrm{~mm} / \mathrm{hr}$, CRP $66.1 \mathrm{mg} / \mathrm{dl}$ (0 - 4.99), LDH 596 U/L (0 - 190), CA 125312.7 U/ml (0 - 35) and CA 15.3 48.1 U/ml (0 - 31.3). On cervical MRI, compression fractures of C6 and T2 vertebrae and spinal cord compression at the level of T2, and osteoblastic metastasis in C 6.7, T1 and T2 vertebrae were seen. On left shoulder MRI, a solid mass of $55 \times 28 \times 25$ mm in size leading to expansion in acromion, humeral intramedullary space-occupying lesion and signal changes compatible with metastasis in humerus were observed (Figure 1 and Figure 2). Oesophagogastroduodenal graphy (OGDG) revealed stenosis in the1/3 middle part of the oesophagus of 8 - 10 centimeters in length and filling defects within the lumen. Endoscopy revealed a fragile soft mass which was nearly completely occluding the lumen between the $24-36^{\text {th }}$ centimeters of the oesophagus. Squamous-cell carcinoma was diagnosed with the pathologic assessment, stent was placed to facilitate feeding and Philadelphia collar was prescribed. Unfortunately, patient deceased at the third month of diagnosis.

\section{Discussion}

Oesophageal cancer is the sixth leading cause of death from cancer in worldwide [4]. The risk of which increases with age, with a mean age of 67 years at the time of diagnosis. It is among the malignancies with poor prognosis since most patients present with advanced disease, therefore establishing the diagnosis as early as possible is of particular importance in order to increase the life expectancy of the sufferers.

More than $90 \%$ of oesophageal cancers are either squamous-cell carcinomas or adenocarcinomas. On rare occacions, other nonepithelial cell carcinomas of the oesephagus (melonomas, leiomyosarcomas, carcinoids and lymphomas) may devolop as well. The pathogenesis of oesophageal cancer remains unclear. Substantial alcohol intake and smoking greatly increases the risk of squamous cell carcinoma, but not adenocarcinoma of the oesophagus [1]. There is a proven association between adenocarcinoma and gastrooesophageal reflux disease with

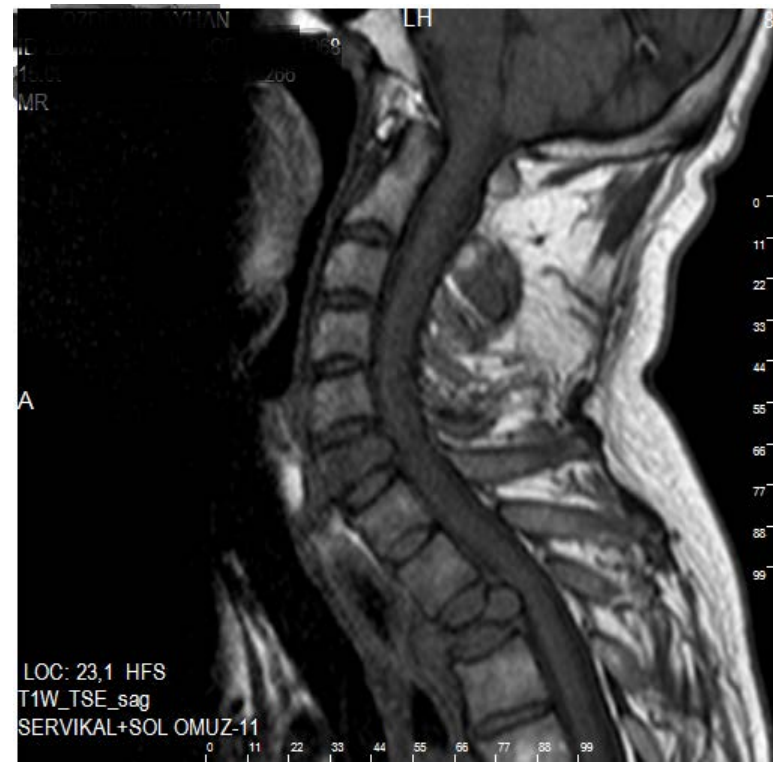

(a)

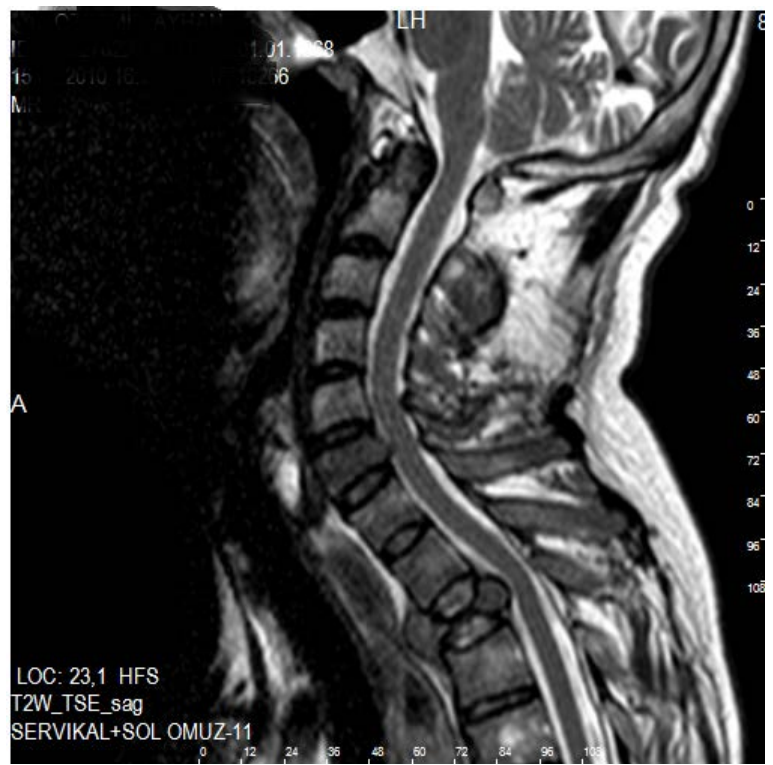

(b)

Figure 1. (a) Sagital T1-weighted and MR images show pathologic compression fracturein cervical and upper thorocic vertebral column. (b) Shows ow-intensity areas in C5 and T1 vertebral columns, suggesting methastatic tumor. 


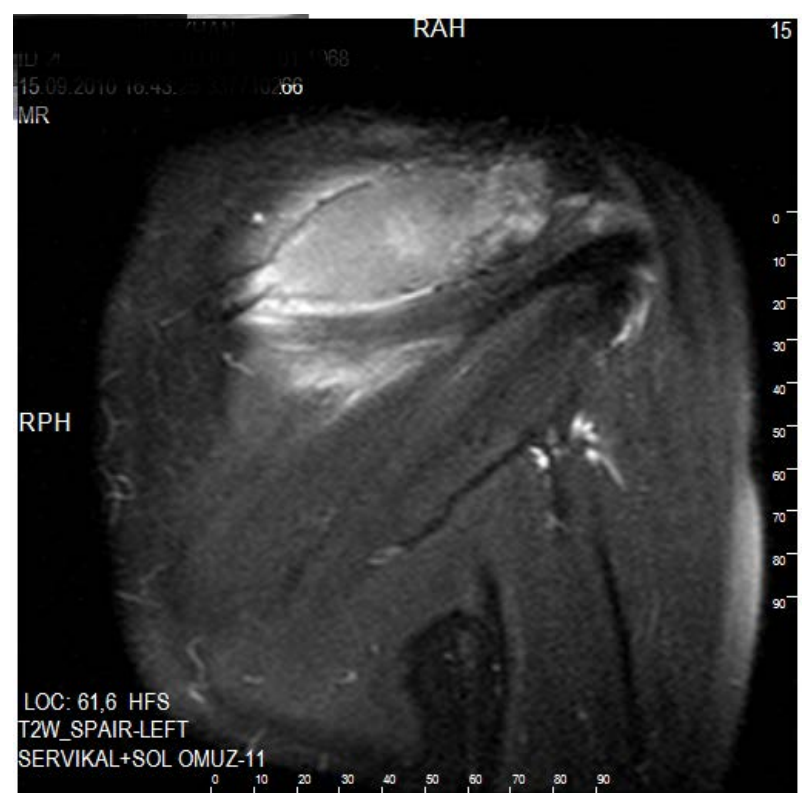

Figure 2. Coronal fat supressed T2-weighted MR shows expansile mass in left acromion.

barret oesophagus [5]. Our patient was a heavy smoker and was also consuming alcohol for nearly 20 years and pathology revealed squamous-cell carcinoma in accordance with the literature.

Although our patient was relatively young at the time of diagnosis, most patients with squamous-cell carcinoma of the oesophagus are males at 60 - 70 years old. Weight loss, chest or back pain when swallowing, gastroesophageal reflux, dyspnea, cough, halitosis, hoarseness and horner sendrome may also be observed as well as dysphagia and odynophagia. Physical examination is usually unremarkable. Oesophagography and upper gastrointestinal system endoscopy can also be used as diagnostic tests. Endoscopic ultrasonography and positron-emission tomography are useful in determining the correct stage and detecting the metastatic disease [6] [7]. OGDG and endoscopy revealed the oesophageal mass and squamous-cell carcinoma was diagnosed with the pathologic assessment in our patient.

Invasion beyond intramucosal stage in squamous cell cancers occurs as a result of direct stromal invasion, intraepidermal spread and intraductal spread. The most common hematogenous spread into the liver, lungs and bones is seen. Bone metastasis from oesophageal cancer are solitary lesions basically because of the short life span (rarely more than three months) of patients [5] [8]. The spine is the most common site of bone metastasis in oesophageal carcinoma as other malignancies, and may occur due to local spreading of the cancer. Rezaee et al. reported five cases with squamous cell carcinoma of oesophagus presenting firstly with bone pain and swelling [9]. Pain due to cervical vertebrae and humerus metastasis was the presenting symptom and in the forefront rather than swallowing difficulty in our case.

Since mean ages of the patients with squamous-cell carcinoma of the oesophagus is 60 - 70 years, pain in neck, low back or any joint can easily be misdiagnosed as degenerative arthritis/spondylosis in many patients unless a careful physical and laboratory examination is performed. This will not only cause a further delay in the diagnosis of an already advanced disease, but also result with malpractice in treatment. Likewise, our patient had also received unnecessary medical treatment and thermal hydrotherapy with the diagnosis of cervical spondylosis.

The most common treatment in patients detected at early stages is oesophagectomy. No standart treatment regimen exists for the metastatic oesophageal carcinoma. Combination of chemotheraphy and radiotheraphy can be used in treatment [1] [5]. Unfortunately, our case was diagnosed at a quite advanced stage, therefore only stent was placed to facilitate feeding and Philadelphia collar was prescribed.

Most of the patients with oesophageal cancer die within the first year of diagnosis. Only 8\% - 20\% of patients survive for 5 years. In the majority of these patients the primary cause of death is metastasis [10]. Likewise, our patient deceased in the third month of diagnosis of the metastatic disease. 


\section{Conclusion}

To conclude, the life expectancy in patients with oesophagus carcinoma is closely related with the stage of the carcinoma. Since the diagnosis is usually established at a late stage, patients generally have poor prognosis. Therefore establishing the diagnosis as early as possible is of particular importance in order to increase the life expectancy of the sufferers. Neck pain, which is one of the most common reasons for admission to Physical medicine and rehabilitation outpatient clinics, can be rarely caused by an underlying malign disease like oesophagus carcinoma. We assume that it should be ruled out especially in patients who define pain characteristics different from that of mechanical pain or who have other signs of malign diseases in order to prevent the delay in diagnosis and malpractice.

\section{References}

[1] Enzinger, P.C. and Mayer, R.J. (2003) Medical Progress: Oesophageal Cancer. New England Journal of Medicine, 23, 2241-2252. http://dx.doi.org/10.1056/NEJMra035010

[2] Daly, J.M., Fry, W.A., Little, A.G., et al. (2000) Esophageal Cancer: Results of an American College of Surgeons Patient Care Evaluation Study. Journal of the American College of Surgeons, 190, 562-572.

[3] Moses, F.M. (1991) Squamous Cell Carcinoma of the Esophagus, Natural History, Incidence, Etiology, and Complications. Gastroenterology Clinics of North America, 4, 703-716.

[4] Pisani, P., Parkin, D.M., Bray, F. and Ferlay, J. (1999) Estimates of the Worldwide Mortality from 25 Cancers in 1990. International Journal of Cancer, 83, 18-29. http://dx.doi.org/10.1002/(SICI)1097-0215(19990924)83:1<18::AID-IJC5>3.0.CO;2-M

[5] Layke, J.C. and Lopez, P.P. (2006) Esophageal Cancer: A Review and Update. American Family Physician, 73, 2187-2194.

[6] Vazquez-Serequez, E., Norton, I.D., Clain, J.E., et al. (2001) Impact of EUS-Guided Fine Needle Aspiration on Lymph Node Staging in Patient with Esophageal Carcinoma. Gastrointestinal Endoscopy, 7, 751-757.

[7] Flamen, P., Lerut, A., Van Cutsem, E., et al. (2000) Utility of Pozitron Emission Tomography the Staging of Patient with Potentiallyoperable Esophageal Carcinoma. Journal of Clinical Oncology, 18, 3202-3210.

[8] Maruka, S., Modi, S. and Singh, S. (2006) Esophagial Cancer: Presentation with Unusual Bone Metastases and Review of Relevant Literature. The Internal Journal of Gastroenterology, $\mathbf{5}$.

[9] Rezae, H. and Bradaran Rahimi, M. (2007) Squamos Cell Carcinoma of Esophagus Presenting as Bone Metastases in Five Cases. The Iranian Journal of Otorhinolary, 19, 9-14.

[10] Flanagan, F.L., Dehdashti, F., Siegel, B.A., Trask, D.D., Sunderasan, S.R., Patterson, G.A., et al. (1997) Staging of Esophageal Cancer with 18F-Fluorodeoxyglucose Positron Emission Tomography. American Journal of Roentgenology, 168, 417-424. http://dx.doi.org/10.2214/ajr.168.2.9016218 